\title{
Impulse wave run-over Experimental benchmark study for numerical modelling
}

\section{Journal Article}

\section{Author(s):}

Fuchs, Helge; Heller, Valentin; Hager, Willi H.

Publication date:

2010

Permanent link:

https://doi.org/10.3929/ethz-b-000024471

\section{Rights / license:}

In Copyright - Non-Commercial Use Permitted

\section{Originally published in:}

Experiments in Fluids 49(5), https://doi.org/10.1007/s00348-010-0836-x 


\title{
Impulse wave run-over: experimental benchmark study for numerical modelling
}

\author{
Helge Fuchs • Valentin Heller • Willi H. Hager
}

Received: 13 May 2009/Revised: 27 January 2010/ Accepted: 27 January 2010/Published online: 6 March 2010

(C) Springer-Verlag 2010

\begin{abstract}
This research intends to provide a detailed data basis for numerical modelling of impulse waves. Three tests are described involving a rectangular wave channel, in which a trapezoidal 'breakwater' was inserted to study wave run-over. In addition, a reference test is also described, in which the breakwater was removed. Two-dimensional impulse waves were generated by means of subaerial granular slides accelerated by a pneumatic landslide generator into the water body. Wave propagation and run-over over the artificial breakwater are documented by a set of high-quality photographs. Water surface profiles were recorded using capacitance wave gages upstream and downstream of the breakwater, and velocity vector fields were determined for the run-over zone by means of Particle Image Velocimetry. The measurements are compared with predictive formulae for wave features and wave non-linearity. The present data set involves both simple channel topography and wave features to allow for numerical simulations under basic laboratory conditions.
\end{abstract}

\section{List of symbols}

a Wave amplitude (L)

$\bar{a} \quad$ Test-averaged wave amplitude (L)

H. Fuchs $(\bowtie) \cdot$ W. H. Hager

Laboratory of Hydraulics, Hydrology and Glaciology (VAW),

ETH Zurich, 8092 Zurich, Switzerland

e-mail: fuchs@vaw.baug.ethz.ch

W. H. Hager

e-mail: hager@vaw.baug.ethz.ch

\section{Heller}

School of Civil Engineering and the Environment,

University of Southampton, Highfield,

Southampton SO17 1BJ, UK

e-mail: v.heller@soton.ac.uk
$a_{\mathrm{M}} \quad$ Maximum wave amplitude (L)

$A_{\mathrm{M}} \quad$ Relative maximum wave amplitude (-)

$b \quad$ Slide width (L)

c Wave celerity $\left(\mathrm{LT}^{-1}\right)$

$c_{1} \quad$ Wave celerity of primary wave $\left(\mathrm{LT}^{-1}\right)$

$c_{2} \quad$ Wave celerity of secondary wave $\left(\mathrm{LT}^{-1}\right)$

$d_{\mathrm{g}} \quad$ Grain diameter (L)

F Slide Froude number (-)

$g \quad$ Gravitational acceleration $\left(\mathrm{LT}^{-2}\right)$

$h \quad$ Still water depth (L)

$H \quad$ Wave height (L)

$L \quad$ Wave length (L)

$m_{\mathrm{s}} \quad$ Slide mass (M)

$M \quad$ Relative slide mass (-)

$\mathrm{P} \quad$ Impulse product parameter (-)

$s \quad$ Slide thickness (L)

$S \quad$ Relative slide thickness (-)

$t \quad$ Time (T)

$T \quad$ Wave period (T)

$\mathrm{T} \quad$ Wave type product (-)

U Ursell number (-)

$v \quad$ Particle displacement velocity $\left(\mathrm{LT}^{-1}\right)$

$V_{\mathrm{s}} \quad$ Slide impact velocity $\left(\mathrm{LT}^{-1}\right)$

$\forall_{\mathrm{s}} \quad$ Bulk slide volume $\left(\mathrm{L}^{3}\right)$

w Breakwater height (L)

$x \quad$ Streamwise coordinate (L)

$x_{\mathrm{M}} \quad$ Streamwise distance of maximum wave amplitude

(L)

$X_{\mathrm{M}} \quad$ Relative distance of maximum wave amplitude (-)

$z \quad$ Vertical coordinate (L)

$\alpha \quad$ Slide impact angle $\left({ }^{\circ}\right)$

$\delta \quad$ Dynamic bed friction angle $\left({ }^{\circ}\right)$

$\Delta t \quad$ Temporal offset (T)

$\varphi^{\prime} \quad$ Internal friction angle $\left(^{\circ}\right)$

$\eta \quad$ Water surface displacement (L) 
$\xi \quad$ Slide profile (L)

$\rho_{\mathrm{g}} \quad$ Grain density $\left(\mathrm{ML}^{-3}\right)$

$\rho_{\mathrm{s}} \quad$ Bulk slide density $\left(\mathrm{ML}^{-3}\right)$

CWG Capacitance wave gage

LDS Laser distance sensor

PIV Particle Image Velocimetry

rms Root-mean-square

\section{Introduction}

Impulse waves may result from slides impacting a water body (Kamphuis and Bowering 1972; Fritz et al. 2003; or Panizzo et al. 2005). These waves may lead to serious damage either during wave run-up at the opposite shore or due to dam overtopping. The 1963 Vaiont disaster is one of the most spectacular cases of impulse waves where an over $100 \mathrm{~m}$ high wave was generated overtopping the Vaiont arch dam by more than $70 \mathrm{~m}$. The downstream located village of Longarone was erased resulting in about 2,000 fatalities (Schnitter 1964).

The basic processes of two-dimensional (2D) impulse wave generation and propagation were investigated during the past decade at Laboratory of Hydraulics, Hydrology and Glaciology VAW, ETH Zurich. This research led to a detailed description of the wave generation and propagation processes, the interaction of granular material with the water body and the development of the free surface and velocity profiles. The governing parameters influencing impulse waves were identified, resulting in the so-called impulse product parameter which includes the main governing parameters. Design formulae to predict impulse wave heights were specified under well-defined limits of application (Heller and Hager 2010a). Despite these recent advances, the formulae only provide an estimation for e.g. complex reservoir bottom topographies or complicated reservoir plan geometries. Numerical modelling of impulse waves is considered an appropriate solution for these cases, given the considerable capacities developed recently. Despite these advances, the available computational procedures need to be calibrated and validated against laboratory observations since reliable field data are rare.

Liu et al. (1991) summarized the evolution of numerical codes on long-wave run-up and pointed at difficulties in modelling wave breaking using the then available methods. Focussing on reflection and transmission coefficients, solitary wave breaking characteristics were investigated by Grilli et al. (1994) using a trapezoidal breakwater similar to that presented herein. Their physically obtained results were confirmed numerically, based on fully non-linear potential flow equations. Huang and Dong (2001) modelled the wave-structure interaction of a solitary wave and a submerged rectangular breakwater using the two-dimensional Navier-Stokes equations discretized by the finiteanalytic method. They evaluated pressure and friction drag exerted on the dike top, caused by viscous flow effects. Data previously produced with the present hydraulic model were already used for calibration or validation by Quecedo et al. (2004), successfully applying the full Navier-Stokes equations complemented with indicator functions dealing especially with impulse wave run-up thereby simulating the 1958 Lituya Bay case experiment of Fritz et al. (2001). Further numerical simulations of the case study of Fritz et al. (2001) were conducted by Mader and Gittings (2002) with a full Navier-Stokes compressible hydrodynamic code, Schwaiger and Higmann (2007) with smoothed particle hydrodynamics (SPH) or Weiss and Wuennemann (2007) with a multi-material hydrocode. Zweifel et al. (2007) used the shallow-water equations to model both wave generation and propagation. Whereas the maximum amplitudes were well reproduced, the temporal wave profiles differed due to the 1D numerical approach in which wave breaking and energy dissipation were not taken into account. Falappi and Gallati (2007) successfully applied the SPH technique resulting in a good agreement of the wave profiles between numerical and physical modelling of the slide impact. Dalrymple and Rogers (2006) pointed at the advantages of SPH particularly under splash or flow separation. Ataie-Ashtiani and Shobeyri (2008) demonstrated the applicability of the incompressible SPH theory to model the slide and impact phases, in addition to wave generation and propagation phases in a rectangular channel. Liu et al. (2008) presented a collection of various numerical models and their advanced application on tsunami run-up calculations.

The present research was undertaken in an effort to present suitable benchmark observations involving relatively simple wave features and topography such that the main effects can be calibrated and validated with a suitable numerical approach. This work intends therefore to add a data set for impulse wave run-over for simplified test conditions in a two-dimensional set-up. The main tests involve wave overtopping over a breakwater in a horizontal rectangular channel for three selected approach flow conditions. To initiate computations, a basic test configuration without breakwater presence is also added.

After a description of the experimental set-up and the slide parameters in Sect. 2, photographs and velocity vector plots are addressed in Sect. 3. The breakwater effect is described in Sect. 4 where wave profiles of tests with and without breakwater presence are compared. The measured wave features are also compared with the results of predictive formulae in Sect. 5. Conclusions summarize the main findings in Sect. 6. 


\section{Experimental methods}

The present results involve physical modelling of hydraulic phenomena. The complex three-phase processes of impulse wave generation and wave run-over including solid, water and air were reduced to a $2 \mathrm{D}$ test set-up. Impulse waves originating from specified test parameters were produced by means of the VAW pneumatic landslide generator (Fritz and Moser 2003). A total of three tests, namely Test 1 to Test 3, were conducted. Each of these was repeated at least three times, allowing to define the test accuracy. Deviations in wave surface profiles and velocity fields were small, as detailed below. The measurements were all recorded in the channel axis. The instrumentation used included (1) laserdistance sensors (LDS) to measure the slide shape and the slide centroid velocity during impact; (2) Particle Image Velocimetry (PIV) to provide the 2D velocity vector fields and (3) capacitance wave gages (CWG) to record the wave profiles at seven locations along the test channel.

For each test, a set of photographs was recorded to document the impulse wave processes and to present combined plots of vector fields plus free surface flow patterns. An overview on the experimental modelling of subaerial landslide generated impulse waves was provided by Heller (2007).

The VAW impulse wave channel is $11 \mathrm{~m}$ long, $1 \mathrm{~m}$ high and $0.5 \mathrm{~m}$ wide. The front wall is of glass, whereas the channel consists of smooth steel plates. For static reasons, a steel beam is vertically mounted at $x / w \cong 12$ (Fig. 1), with the streamwise coordinate $x$ measured from the intersection of the still water surface and the channel front end, and the crest height $w$ of the breakwater. The channel was equipped with a trapezoidal PVC 'breakwater' of height $w=0.300 \mathrm{~m}$, crest length $0.300 \mathrm{~m}(1 w)$ and total length $1.500 \mathrm{~m}(5 w)$ inserted at $x=1.95 \mathrm{~m}(6.5 w)$. Both the front and back slopes were 1:2. The breakwater centre line consisted of transparent acrylic glass allowing the laser light sheet to reach the downstream, the crest top and the upstream sections of the breakwater (Fig. 1). Standard values for the equivalent sand roughness coefficients were estimated to $0-0.003 \mathrm{~mm}$ for glass and plexiglass, and 0.01-0.1 mm for smooth steel plates, respectively (Montes 1998, Reeve et al. 2004).

The landslides consisted of granular material accelerated by the pneumatic landslide generator. The slide parameters are shown in Table 1 including slide impact velocity $V_{\mathrm{s}}$, slide mass $m_{\mathrm{s}}$, slide thickness $s$, bulk slide volume $\forall_{\mathrm{s}}$ taken herein constant to $0.033 \mathrm{~m}^{3}$, grain diameter $d_{\mathrm{g}}$, grain density $\rho_{\mathrm{g}}$, bulk slide density $\rho_{\mathrm{s}}$, slide impact angle $\alpha$ taken herein constant to $90^{\circ}$ from the horizontal, dynamic bed friction angle $\delta$ and internal friction angle $\varphi^{\prime}$. The still water depths considered were $h=0.200,0.300$ and $0.450 \mathrm{~m}$, corresponding to $(2 / 3) w,(1) w$ and $(3 / 2) w$. Note that these are larger than the minimum still water depth required to avoid significant scale effects in the wave generation phase (Heller et al. 2008).

The governing dimensionless test parameters are also listed in Table 1, including the slide Froude number $\mathrm{F}=V_{\mathrm{s}} /(g h)^{1 / 2}$ as the ratio between slide centroid velocity and shallow-water wave celerity, the relative slide thickness $S=s / h$ and the relative slide mass $M=m_{\mathrm{s}} /\left(\rho_{\mathrm{s}} b h^{2}\right)$. Water temperature was kept under laboratory conditions between $21^{\circ}$ and $23^{\circ}$. The starting time of a test was set to $t=0.0 \mathrm{~s}$ when the slide front reached the still water surface. Figure 2 shows the scanned slide profiles of Test 2 for

Table 1 Governing test parameters

\begin{tabular}{lllllllll}
\hline & $\begin{array}{l}h \\
(\mathrm{~m})\end{array}$ & $\begin{array}{l}V_{\mathrm{s}} \\
(\mathrm{m} / \mathrm{s})\end{array}$ & $\begin{array}{l}m_{\mathrm{s}} \\
(\mathrm{kg})\end{array}$ & $\begin{array}{l}s \\
(\mathrm{~m})\end{array}$ & $\begin{array}{l}\forall_{\mathrm{s}} \\
\left(\mathrm{m}^{3}\right)\end{array}$ & $\begin{array}{l}d_{\mathrm{g}} \\
(\mathrm{m})\end{array}$ & $\begin{array}{l}\rho_{\mathrm{g}} \\
\left(\mathrm{kg} / \mathrm{m}^{3}\right)\end{array}$ & $\begin{array}{l}\rho_{\mathrm{s}} \\
\left(\mathrm{kg} / \mathrm{m}^{3}\right)\end{array}$ \\
\hline Test 1 & 0.200 & 5.69 & 55.0 & 0.24 & 0.033 & 0.004 & 2,640 & 1,650 \\
Test 2 & 0.300 & 8.28 & 20.6 & 0.24 & 0.033 & 0.005 & 955 & 610 \\
Test 3 & 0.450 & 6.24 & 20.5 & 0.24 & 0.033 & 0.005 & 955 & 610 \\
\hline & $\alpha$ & $\delta$ & $\varphi^{\prime}$ & $\mathrm{F}$ & $S$ & $M$ & $\mathrm{P}$ & \\
& $\left({ }^{\circ}\right)$ & $\left({ }^{\circ}\right)$ & $\left(^{\circ}\right)$ & $(-)$ & $(-)$ & $(-)$ & $(-)$ & \\
\hline Test 1 & 90 & 24 & 34 & 4.06 & 1.20 & 2.9 & 2.74 & \\
Test 2 & 90 & 20 & 27 & 4.83 & 0.80 & 0.5 & 1.69 & \\
Test 3 & 90 & 20 & 27 & 2.97 & 0.53 & 0.2 & 0.69 & \\
\hline
\end{tabular}

Fig. 1 Schematic test set-up with (1) slide box of pneumatic landslide generator, (2) accelerated granular slide, (3) $\mathrm{LDS}_{-1}$ and $\mathrm{LDS}_{0}$, (4) trapezoidal breakwater and (5) mirror reflecting laser light sheet in field of view

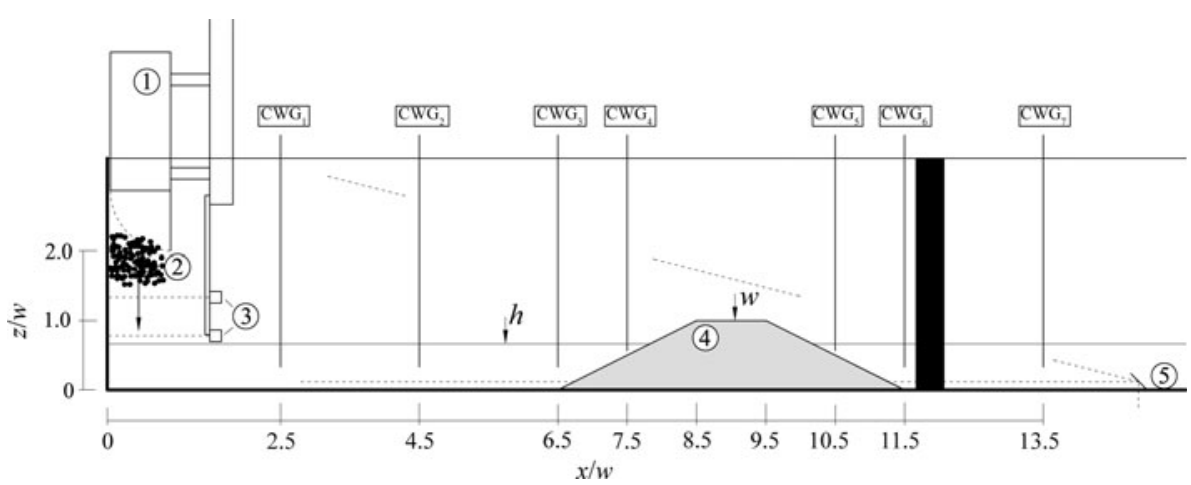




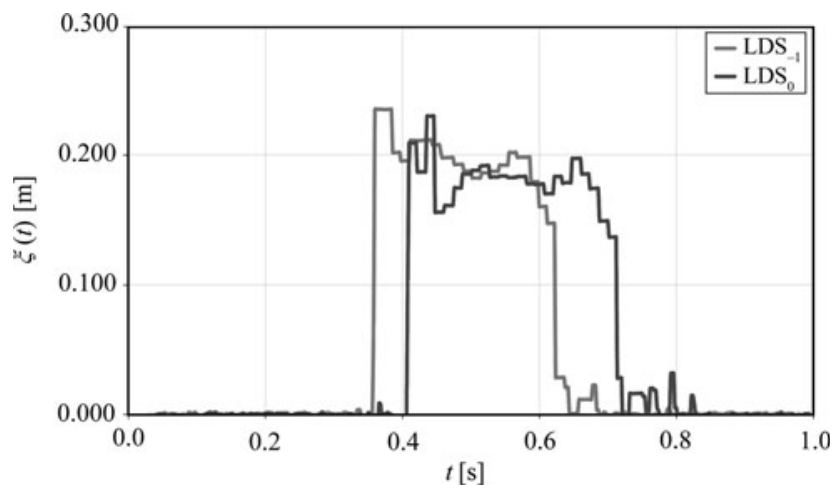

Fig. 2 Slide profiles $\xi(t)$ scanned prior $\left(\operatorname{LDS}_{-1}\right)$ and during impact $\left(\mathrm{LDS}_{0}\right)$

$\mathrm{LDS}_{0}$ located at the water surface and $\mathrm{LDS}_{-1}$ located $0.333 \mathrm{~m}$ above, resulting in a slide impact velocity of $V_{\mathrm{s}}=8.28 \mathrm{~m} / \mathrm{s}$ and a slide thickness of $s=0.24 \mathrm{~m}$. The stepwise shape of the plot results from the measurement resolution of $500 \mathrm{~Hz}$ in combination with the LDS sample frequency of $100 \mathrm{~Hz}$. The exact wave generation process is addressed e.g. by Fritz et al. (2003) or Heller (2007), and the focus of this study is one step further downstream, namely wave run-over. The velocity and free surface profiles at the left boundary in the presented figures will be specified below.

The wave characteristics were measured over a length of $3.30 \mathrm{~m}$ using seven CWGs. Three were installed upstream, two along and two downstream of the 'breakwater', respectively (Fig. 1). The generated impulse waves were either bore-, cnoidal- or Stokes-like according to an optical wave type inspection or the wave type diagrams of Heller and Hager (2010b).

The PIV system consisted of a $225 \mathrm{~mJ}$ double Nd:YAG laser with a pulse rate of $15 \mathrm{~Hz}$ to illuminate the added seeding particles in the field of view. The laser beams entered the channel through the glassed channel bottom and were reflected upstream by a $2^{\prime \prime}$ mirror (Fig. 1). The round seeding particles of diameter $d_{\mathrm{g}}=1.6 \mathrm{~mm}$ and density $\rho_{\mathrm{g}}=1,006 \mathrm{~kg} / \mathrm{m}^{3}$ were made of Grilamid ${ }^{\circledR}$, a polyamide plastic with a refractive index of 1.52. Their movement was captured by two 1MP CCD cameras mounted orthogonally to the light sheet plane. The combined field of view of both cameras was $1.78 \mathrm{~m}$ wide. One set of vector information presented below was thus composed of two image-pairs, for the up- and downstream regions captured under identical test conditions. Hence, the composed field of view was up to $9.0 \mathrm{w}$. Vectors were obtained with the software DaVis ${ }^{\circledR} 6.2$ and 6.3 with a resolution of $12.44 \times 12.44 \mathrm{~mm}$ in the object plane as a result of a recursive decreasing interrogation window size of $64 \times 64$ to $32 \times 32$ pixels with a final overlap of $50 \%$. To keep the vector plots evident, only each ninth vector was considered, decreasing the spatial resolution to $37.3 \times 37.3 \mathrm{~mm}$. A high pass and a median filter were applied as standard pre- and post-processing techniques. Vectors having a rms value larger than three times the rms of their neighbours were removed and replaced by a median vector during post-processing. The obviously spurious vectors were removed manually to maintain clearness. A detailed description of the applied PIV system is given by Fritz et al. (2003).

Heller and Hager (2010a) identified the impulse product parameter $P$ as the relevant dimensionless parameter combination to describe the generation and propagation of subaerial landslide generated impulse waves. This parameter is defined as

$\mathrm{P}=\mathrm{F} S^{1 / 2} M^{1 / 4}\{\cos [(6 / 7) \alpha]\}^{1 / 2}$.

A run-over wave amplitude of $a=0.5 \mathrm{w}$ was attempted to generate a distinct breakwater overtopping. Table 2 states both the selected and finally used (subscript used) impulse product parameters $P$. Differences originated from basic test limitations such as the available box volume or the selected slide impact angle $\alpha$. The range of $P$ between 0.5 and 3 was considered an optimum in terms of wave amplitude generated, wave types observed and the run-over flow characteristics. The calculated (subscript calc) relative maximum wave amplitude $A_{\mathrm{M}}=(4 / 9) \mathrm{P}^{4 / 5}$ according to Heller and Hager (2010a) was overestimated by a factor of 1.08-1.28 (Table 2). The data were within the specified overall scatter of $30 \%$, although the CWGs were located closer to the slide impact zone than in Heller and Hager (2010a).

An overall good test repetition accuracy was achieved, as stated in Table 3 for the wave amplitude features including the average of three test repetitions of each of the three individual test runs, the root-mean-square rms and the relative value $\mathrm{rms} / \bar{a}$ with $\bar{a}$ as test-average wave amplitude.

Table 2 Calculated wave amplitude characteristics according to Heller and Hager (2010a)

\begin{tabular}{|c|c|c|c|c|c|c|c|c|c|c|c|}
\hline & $\begin{array}{l}h \\
(\mathrm{~m})\end{array}$ & $\begin{array}{l}a / w \\
(-)\end{array}$ & $\begin{array}{l}\mathrm{P}(a=0.15 \mathrm{~m}) \\
(-)\end{array}$ & $\begin{array}{l}P_{\text {used }} \\
(-)\end{array}$ & $\begin{array}{c}A_{\mathrm{M}} \\
(-)\end{array}$ & $\begin{array}{l}a_{\mathrm{M}, \text { calc }} \\
(\mathrm{m})\end{array}$ & $\begin{array}{l}a_{\mathrm{M}} \\
(\mathrm{m})\end{array}$ & $\begin{array}{l}a_{\mathrm{M}, \mathrm{calc}} / a_{\mathrm{M}} \\
(-)\end{array}$ & $\begin{array}{l}X_{\mathrm{M}} \\
(-)\end{array}$ & $\begin{array}{l}x_{\mathrm{M}} \\
(\mathrm{m})\end{array}$ & $\begin{array}{l}x_{\mathrm{M}} / w \\
(-)\end{array}$ \\
\hline Test 1 & 0.200 & 0.75 & 2.11 & 2.74 & 1.00 & 0.20 & 0.185 & 1.08 & 9.1 & 1.82 & 6.07 \\
\hline Test 2 & 0.300 & 0.50 & 1.41 & 1.69 & 0.68 & 0.20 & 0.168 & 1.21 & 7.2 & 2.15 & 7.15 \\
\hline Test 3 & 0.450 & 0.33 & 0.94 & 0.69 & 0.33 & 0.15 & 0.116 & 1.28 & 4.6 & 2.06 & 6.85 \\
\hline
\end{tabular}


Table 3 Observed test-averaged wave amplitudes $\bar{a}$ with maximum deviations in bold

\begin{tabular}{|c|c|c|c|c|c|c|c|c|c|c|}
\hline & \multicolumn{3}{|l|}{ Test 1} & \multicolumn{3}{|l|}{ Test 2} & \multicolumn{3}{|l|}{ Test 3} \\
\hline \multicolumn{2}{|c|}{ First wave peak at $x=\ldots \mathrm{m}$} & \multirow{2}{*}{$\begin{array}{l}\begin{array}{l}\bar{a} \\
(\mathrm{~m})\end{array} \\
0.379\end{array}$} & \multirow{2}{*}{$\begin{array}{l}\begin{array}{l}\mathrm{rms} \\
(\mathrm{m})\end{array} \\
0.0128\end{array}$} & \multirow{2}{*}{$\frac{\begin{array}{l}\mathrm{rms} / \bar{a} \\
(\%)\end{array}}{3.4}$} & \multirow{2}{*}{$\begin{array}{l}\begin{array}{l}\bar{a} \\
(\mathrm{~m})\end{array} \\
0.286\end{array}$} & \multirow{2}{*}{$\begin{array}{l}\begin{array}{l}\mathrm{rms} \\
(\mathrm{m})\end{array} \\
0.0234\end{array}$} & \multirow{2}{*}{$\begin{array}{l}\begin{array}{l}\mathrm{rms} / \bar{a} \\
(\%)\end{array} \\
8.2\end{array}$} & \multirow{2}{*}{$\begin{array}{l}\begin{array}{l}\bar{a} \\
(\mathrm{~m})\end{array} \\
0.173\end{array}$} & \multirow{2}{*}{$\begin{array}{l}\mathrm{rms} \\
(\mathrm{m})\end{array}$} & \multirow{2}{*}{$\begin{array}{l}\begin{array}{l}\mathrm{rms} / \bar{a} \\
(\%)\end{array} \\
\mathbf{1 3 . 9}\end{array}$} \\
\hline $\mathrm{CWG}_{1}$ & 0.750 & & & & & & & & & \\
\hline $\mathrm{CWG}_{2}$ & 1.350 & 0.185 & 0.0054 & 2.9 & 0.168 & 0.0127 & 7.5 & 0.116 & 0.0024 & 2.1 \\
\hline $\mathrm{CWG}_{3}$ & 1.950 & 0.223 & 0.0068 & 3.0 & 0.154 & 0.0076 & 5.0 & 0.090 & 0.0003 & 0.3 \\
\hline $\mathrm{CWG}_{4}$ & 2.250 & 0.223 & 0.0055 & 2.4 & 0.157 & 0.0037 & 2.3 & 0.085 & 0.0006 & 0.7 \\
\hline $\mathrm{CWG}_{5}$ & 3.150 & 0.093 & 0.0026 & 35.0 & 0.104 & 0.0082 & 7.9 & 0.069 & 0.0022 & 3.2 \\
\hline $\mathrm{CWG}_{6}$ & 3.450 & 0.133 & 0.0056 & 4.2 & 0.099 & 0.0084 & 8.5 & 0.074 & 0.0019 & 2.6 \\
\hline $\mathrm{CWG}_{7}$ & 4.050 & 0.102 & 0.0050 & 4.9 & 0.100 & 0.0078 & 7.8 & 0.070 & 0.0019 & 2.7 \\
\hline
\end{tabular}

Small inaccuracies were only observed for Test 1 at $\mathrm{CWG}_{5}$ with $h=0.200 \mathrm{~m}$, where the zone downstream of the breakwater involves measurement problems caused by massive mixing due to jet impact and the corresponding two-phase flow generation (Fig. 3c). $\bar{a}$ scatters less than $\pm 5 \%$ if $\mathrm{CWG}_{5}$ is excluded. For Test 2 the maximum scatter amounted to $\pm 8.5 \%$, whereas for Test 3 air entrainment produced a larger scatter of $\pm 13.9 \%$ at $\mathrm{CWG}_{1}$ close to the slide impact zone. The remaining wave amplitudes not affected by the slide impact process involve a scatter of less than $\pm 3.2 \%$ for Test 3 , however.

\section{Experimental results}

\subsection{Photographs}

For each test, a set of photographs is presented below, illustrating the wave overflow features. They were captured using a NIKON D70 camera with a sample rate of $3 \mathrm{~Hz}$. The image distortion caused by the wide angle lens of $14 \mathrm{~mm}$ focal length was manually rectified using commercial photo editing software. Since photo acquisition was triggered independently from the measuring system, time inscription was identified by visual comparison to PIV images. Note that time steps of photographs are not identical to velocity vector fields presented in Subsect. 3.2, due to the different sample frequencies.

Figure 3 shows a photo sequence of wave run-over for the smallest still water depth of $h=0.200 \mathrm{~m}$ (Test 1). The front of the approaching, still developing bore-like wave is visible in Fig. 3a, along with large splash due to the wave generation process. The wave crest is sharp-peaked and the wave profile asymmetric with a steeper front than the wave back. Note that slide deposit on the channel bottom is still in progress. In Fig. 3b, the wave front has steepened due to decreasing local flow depth, whereas the wave back has almost the same slope as in Fig. 3a. The wave crest is about to break as the breakwater crest is reached. Water splash and granular material from the wave generation process are observed impinging onto the downstream water body having a negligible effect on the CWG measurements. The slide deposit reaches by now its final position.

Figure $3 \mathrm{c}$ shows the water flow over the breakwater as a jet. Note that the surface profile is smooth, in contrast to Fig. 3a and b. The flow separates at the downstream breakwater crest edge thereby entraining air into the breakwater crest zone and the tailwater impact location. The jet plunges into the still tailwater beyond the breakwater just prior to further wave generation. Figure $3 d$ marks the start of the two-phase mixing zone caused by the large amount of air entrained from the collapsing jet in the tailwater reach of the breakwater. This air is responsible for massive laser light scattering during PIV measurement, resulting in poorly illuminated images upstream from the breakwater due to lack of laser light. The impulse transferred to the downstream flow generates there a bore-like impulse wave propagating in the downstream direction. Note that the flow depth over the breakwater reduces due to lack of fluid and a secondary wave propagates from the channel start following reflection of the initial impulse wave generation.

Figure $3 \mathrm{e}$ and $\mathrm{f}$ present the highly turbulent two-phase mixing zones. The bore approaching from the channel start is seen to be stronger than the downflow from the breakwater on the one hand, whereas the bore-like wave downstream of the breakwater has left the field of view on the other hand.

Figure 4 shows a photo sequence of Test 2, with results quite similar as shown in Fig. 3 for Test 1. In Fig. 4a and b, a solitary-like instead of a developing bore-like wave propagates towards the breakwater, with a symmetrical wave profile and almost without a wave trough (Fig. 10a). Note that there is practically no splash and granular material on the tailwater surface, because Test 2 was run with sediment lighter than water, which is, however, visible in the upstream reach due to the high slide impact velocity of $V_{\mathrm{s}}=8.28 \mathrm{~m} / \mathrm{s}$ (Table 1$)$. 
Fig. 3 Photo sequence of Test 1; impulse wave run-over for $h=0.200 \mathrm{~m}$ at various time steps
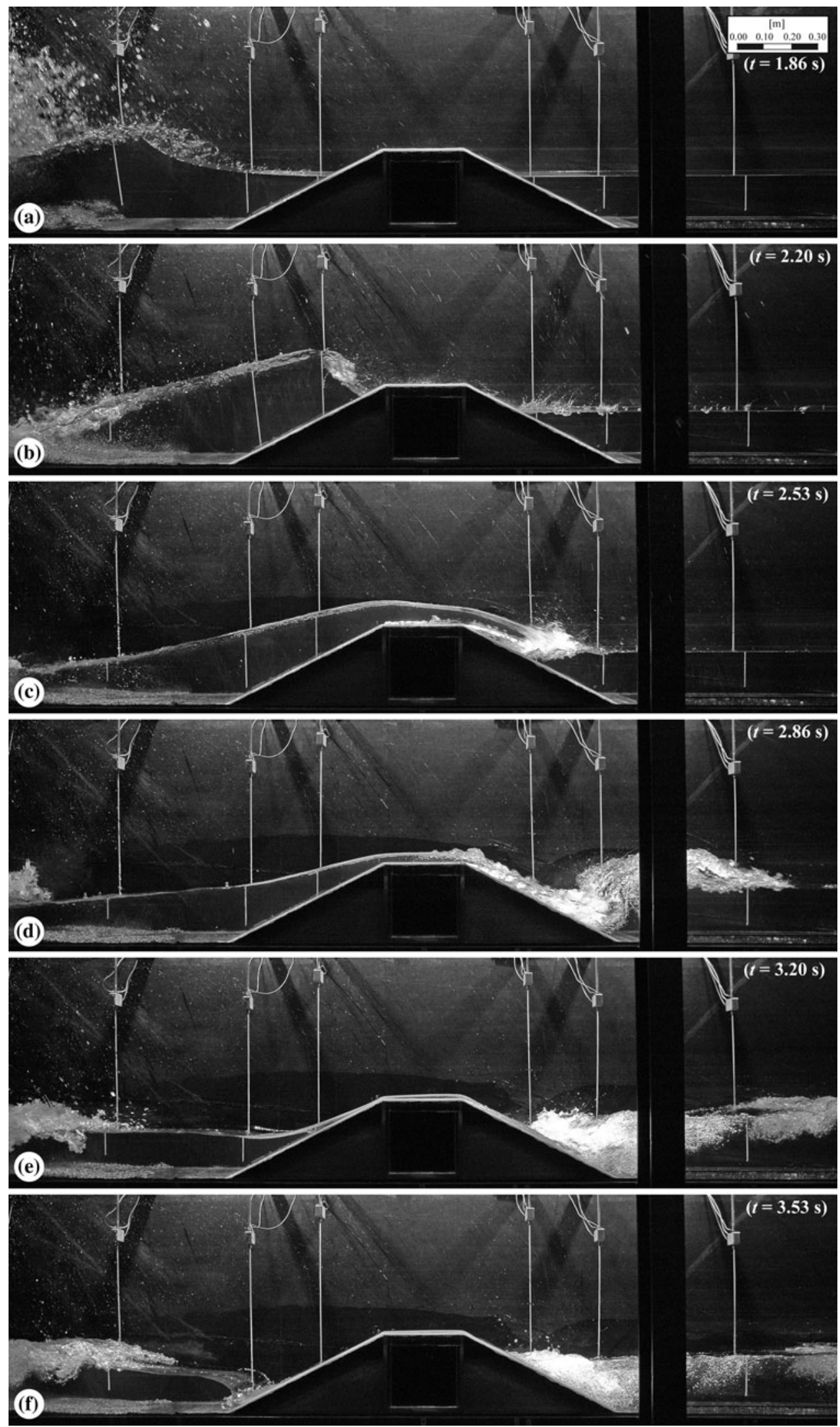
Fig. 4 Photo sequence of Test 2; impulse wave run-over for $h=0.300 \mathrm{~m}$ at various time steps
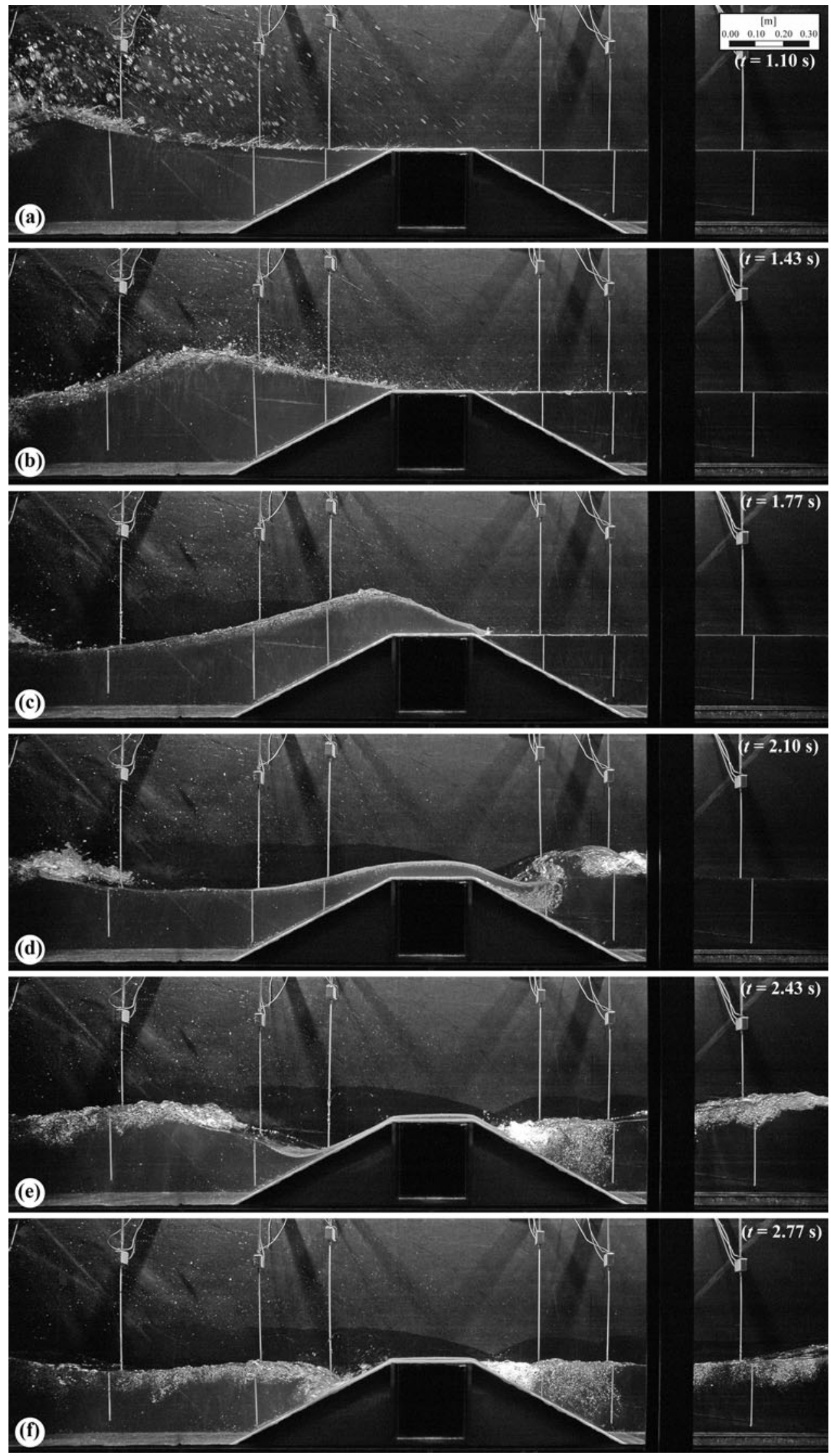
In Fig. 4c, the wave front has just reached the end of the horizontal breakwater crest. The wave profile is still symmetric with a wave amplitude of roughly $0.5 w$. Almost no wave trough is observed in the wave profile upstream the breakwater, and the tailwater is not yet reached. Figure $4 d$ shows the arrival of the secondary wave on the left side, and the jet generated in the tailwater due to breakwater overtopping. In Test 2 , this results in a surface jet, whereas a plunging jet was formed in Test 1 . The impulse transferred to the tailwater finally results in a weak bore-like wave propagating out of Fig. 4e. Figure $4 \mathrm{e}$ further shows the arrival of the secondary bore-like wave towards the breakwater, whose crest has almost completely decayed by now. Note again the massive two-phase mixing zone at the opposite breakwater side. Figure $4 \mathrm{f}$ finally shows the run-up of the secondary wave onto the breakwater from the left and the tail of the weak bore at the right side. Reflections until complete standstill of water were not further investigated.

Figure 5 shows the photo sequence relating to $h=0.450 \mathrm{~m}$. Compared to Tests 1 and 2, the relative wave heights and air entrainment are smaller. In Fig. 5a-d, the primary wave crest passes the breakwater. The initial Stokes-like wave is eventually transforming into a cnoidallike wave as the breakwater is passed. Note the asymmetric wave profiles. In Fig. 5e, the secondary wave from upstream enters the field of view along with return flow from the breakwater, creating in Fig. 5f a bore-like front towards the breakwater. The primary wave crest is seen to leave the field of view at the right side. The wave then steepens as the breakwater top zone is reached generating a bore-like wave which is about to break (Fig. 5f) and developing as a plunging breaker in Fig. 5g. The jet impacts the tailwater by creating a large air pocket. In Fig. 5h, the enclosed air pocket is still visible along with a surface roller propagating into the tailwater. Air bubbles located at the tailwater breakwater slope indicate reversed flow along its tailwater slope while the surface roller generated by impact of the surface jet propagates into the tailwater. The air entrained is slowly detrained from the flow (Fig. 5i-1). Note also the tertiary and further waves reflected from the channel start reaching in Fig. 5j the breakwater crest.

\subsection{Velocity vector fields}

Following the above description of the photo sequences, the velocity vector fields for Tests 1-3 are presented including the boundary conditions on the left side of each field of view. Particular attention is given to the features of the velocity distributions, as this aspect was not yet covered. Velocities are normalized by the shallow-water wave celerity $c=(g h)^{1 / 2}$ included in the upper right corner of the vector plots.
Figure 6 relates to Test 1. The flow from the channel start is seen to enter the field of view in Fig. 6a with an almost horizontal velocity distribution except for the wave crest zone. Whereas in Fig. $6 \mathrm{a}-\mathrm{c}$ all vectors are directed into the streamwise direction, Fig. $6 \mathrm{~d}$ indicates flow reversal at $x / w \cong 5.5$ because of the pressure gradient exerted from slide impact. Note also the maximum velocities of $v=2.4(\mathrm{gh})^{1 / 2}$ at the wave front. Figure 6e relates to the formation of the plunging jet into the tailwater, which separates from the breakwater thereby generating a bore-like wave (Fig. 6f). Note the large surface bore velocities and that the entire tailwater flow is reversed in the streamwise direction without visible recirculation. In contrast, the flow in the upstream reach is seen to recirculate at $x / w \cong 7.0$ in Fig. $6 \mathrm{e}$ and $x / w \cong 8.1$ in Fig. 6 .

This sequence could pretend that the maximum wave amplitude remains nearly constant as the breakwater is passed, namely $a / w \cong 1.40$ in Fig. $6 \mathrm{~b}$ to $a / w \cong 1.45$ in Fig. $6 \mathrm{c}$ to again $a / w \cong 1.40$ in Fig. $6 \mathrm{~d}$ to finally $a / w \cong 1.30$ in Fig. 6e and f. Figure 3, however, indicates that significant air is entrained into the wave front resulting in air-water mixture flow of high air concentration along with a considerable energy dissipation. The wave celerities are given below.

Figure 7 relates to Test 2. Compared to Test 1 , all wave crests are seen to be less sharp, and velocities are smaller. The wave approaching the breakwater in Fig. $7 a$ and $b$ reaches its maximum amplitude in Fig. 7c, in which the velocity vectors in the wave front portion are directed remarkably horizontal. Note again the surface flow reversals at $x / w \cong 4.8,6.5,7.9,8.5$ and 8.9 in Fig. $7 b-f$, respectively. Figure $7 \mathrm{~d}$ shows the generation of the borelike tailwater wave due to plunging jet formation with velocities of $v=1.1(\mathrm{gh})^{1 / 2}$, thereby creating a cavity between the bore and the breakwater. The latter generates a recirculating, smaller bore which eventually impacts the breakwater from the tailwater entraining considerable air due to jet impact (Fig. 7f). The primary bore has then already left the field of view.

Figure 8 relates to Test 3 . The primary wave approaches the breakwater with an increased crest celerity of $c_{1} \approx 2.1 \mathrm{~m} / \mathrm{s}$, as compared with $c_{1} \approx 1.9 \mathrm{~m} / \mathrm{s}$ for Tests 1 and 2. As for these, the velocity directions are nearly horizontal below the wave crest, whereas the surface flow reversal is located here at $x / w \cong 5.5,6.5,7.5,8.3$ and 9.1 in Fig. 8b-f, respectively. The relative maximum wave amplitudes are $a / w \cong 1.9,1.8,1.8,1.7,1.75$ and 1.75 in Fig. 8a-f, respectively. The breakwater presence therefore slightly reduces the wave amplitude as the wave crest passes. The primary wave leaves the field of view in Fig. 8g.

The secondary wave from the channel start enters the field of view in Fig. 8f. When compared with the primary 
Fig. 5 Photo sequence of Test 3 ; impulse wave run-over for $h=0.450 \mathrm{~m}$ at various time steps
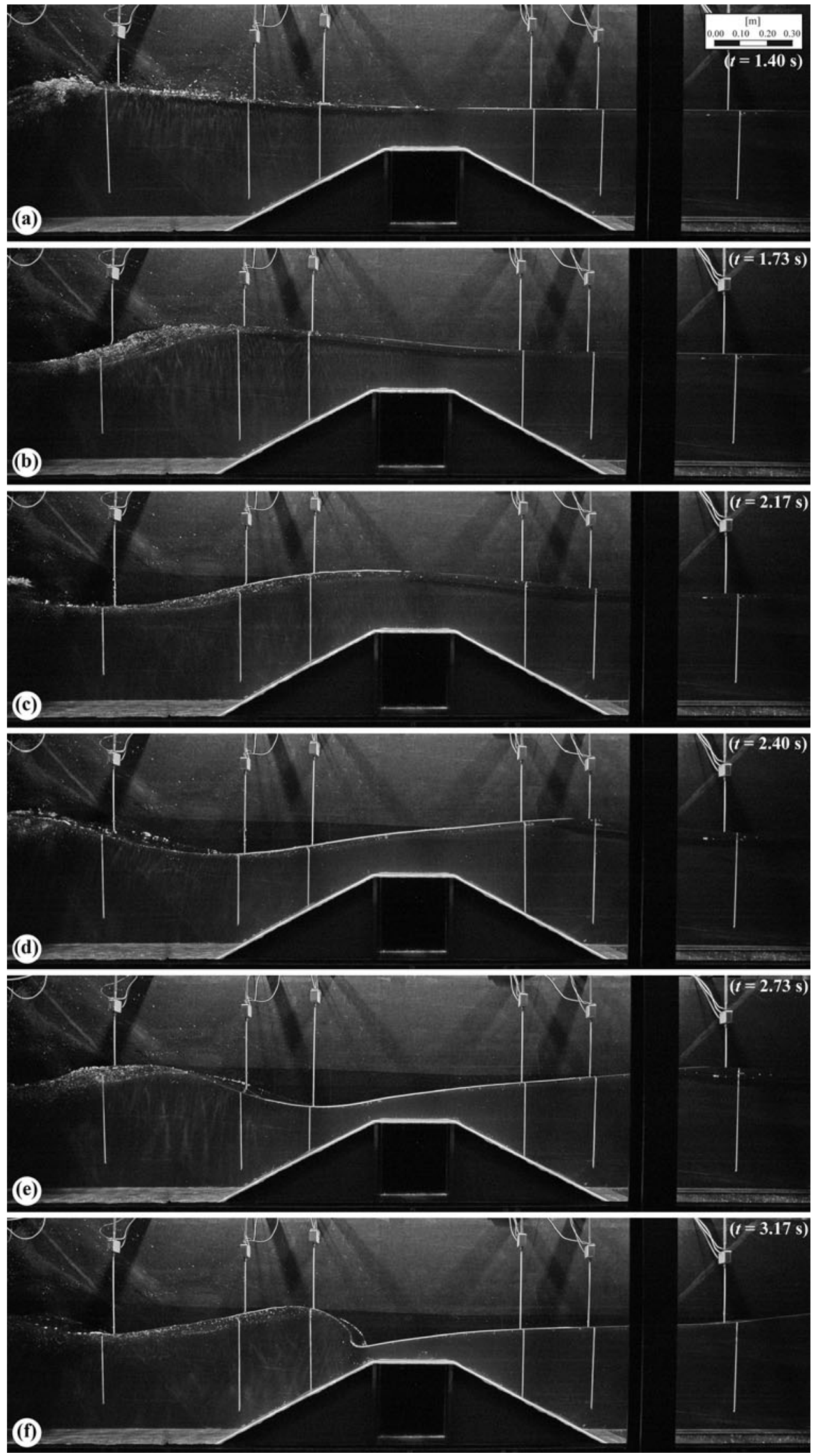
Fig. 5 continued
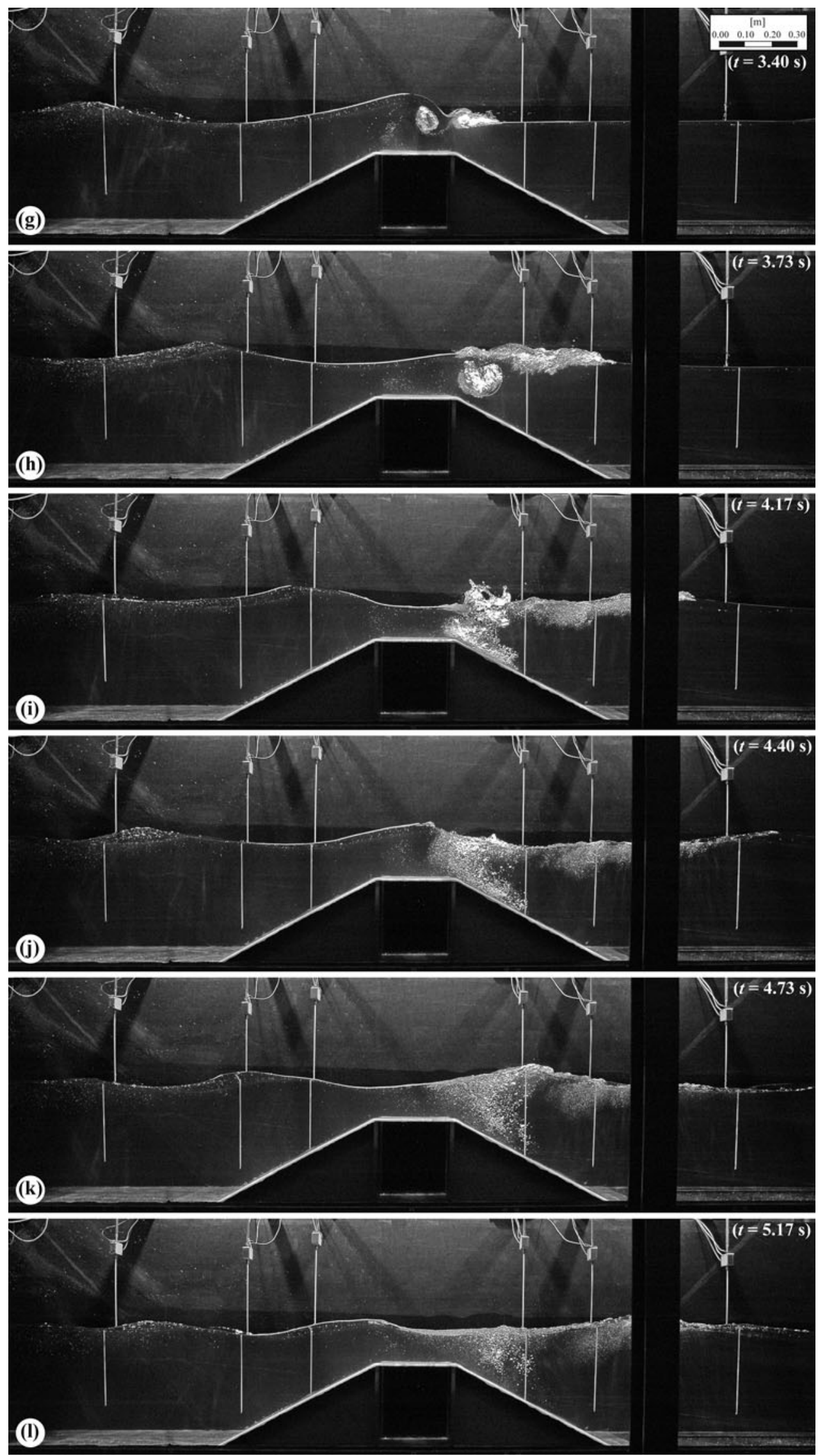
Fig. 6 Velocity vector fields for Test 1
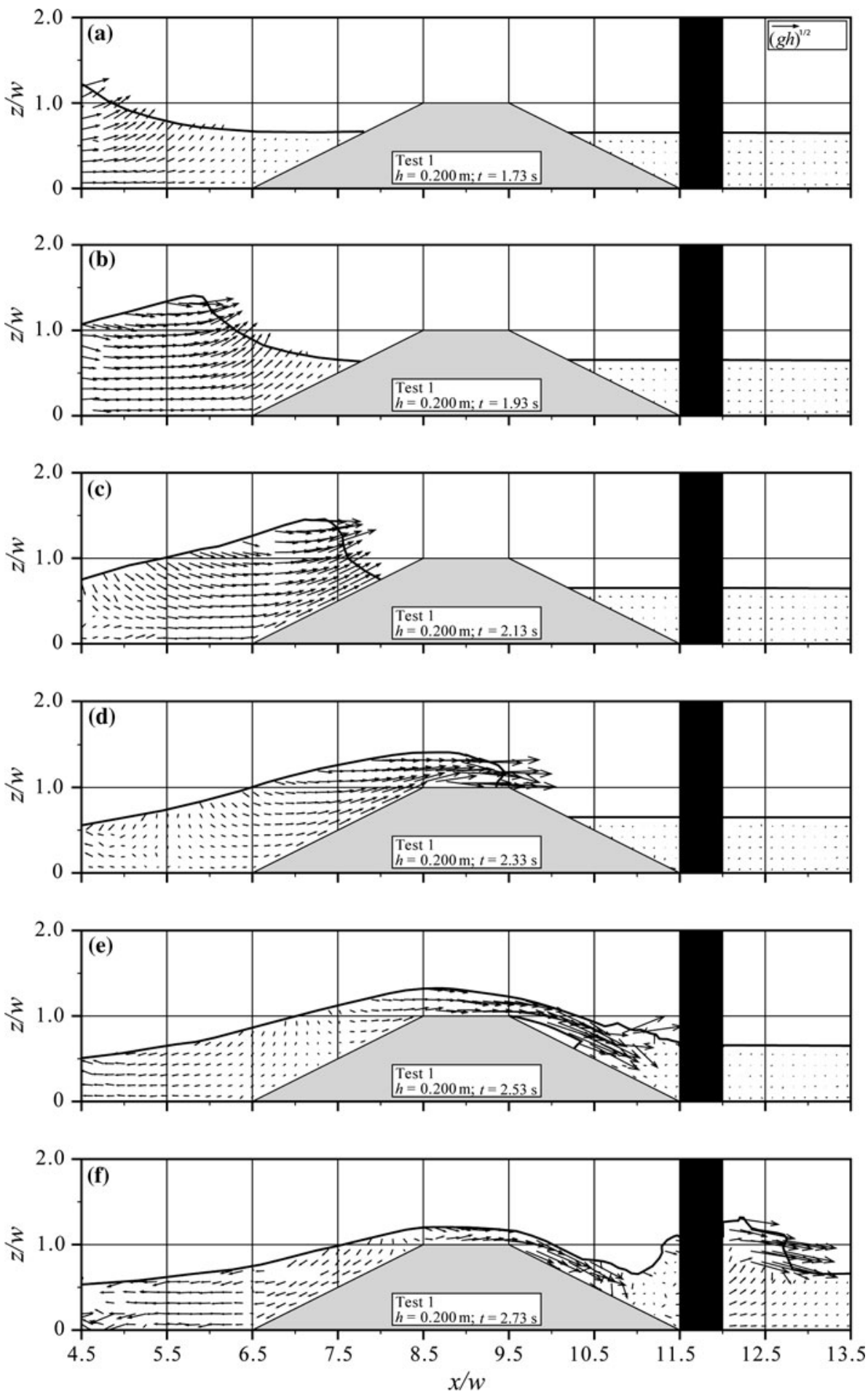

wave, it is almost of identical amplitude but much steeper, in contrast to the primary wave of Test 2 . The wave trough between the primary and secondary wave located in the breakwater vicinity transforms the secondary wave to a bore-like wave from Fig. $8 \mathrm{~g}$ to i generating wave breaking in Fig. 8i and subsequent surface roller formation in the next plots. The maximum particle velocity is seen to be $v=0.8(g h)^{1 / 2}$ in Fig. $8 \mathrm{j}$ inside the roller. Note that Fig. 8 includes only the photographs of Fig. 5a-i.

The amplitudes of the secondary wave are $a / w \cong 1.8$, $1.7,1.8,1.8,1.7$ and 1.65 in Fig. $8 \mathrm{~g}-1$, respectively, i.e. slightly less than of the primary wave. The surface flow 
Fig. 7 Velocity vector fields for Test 2
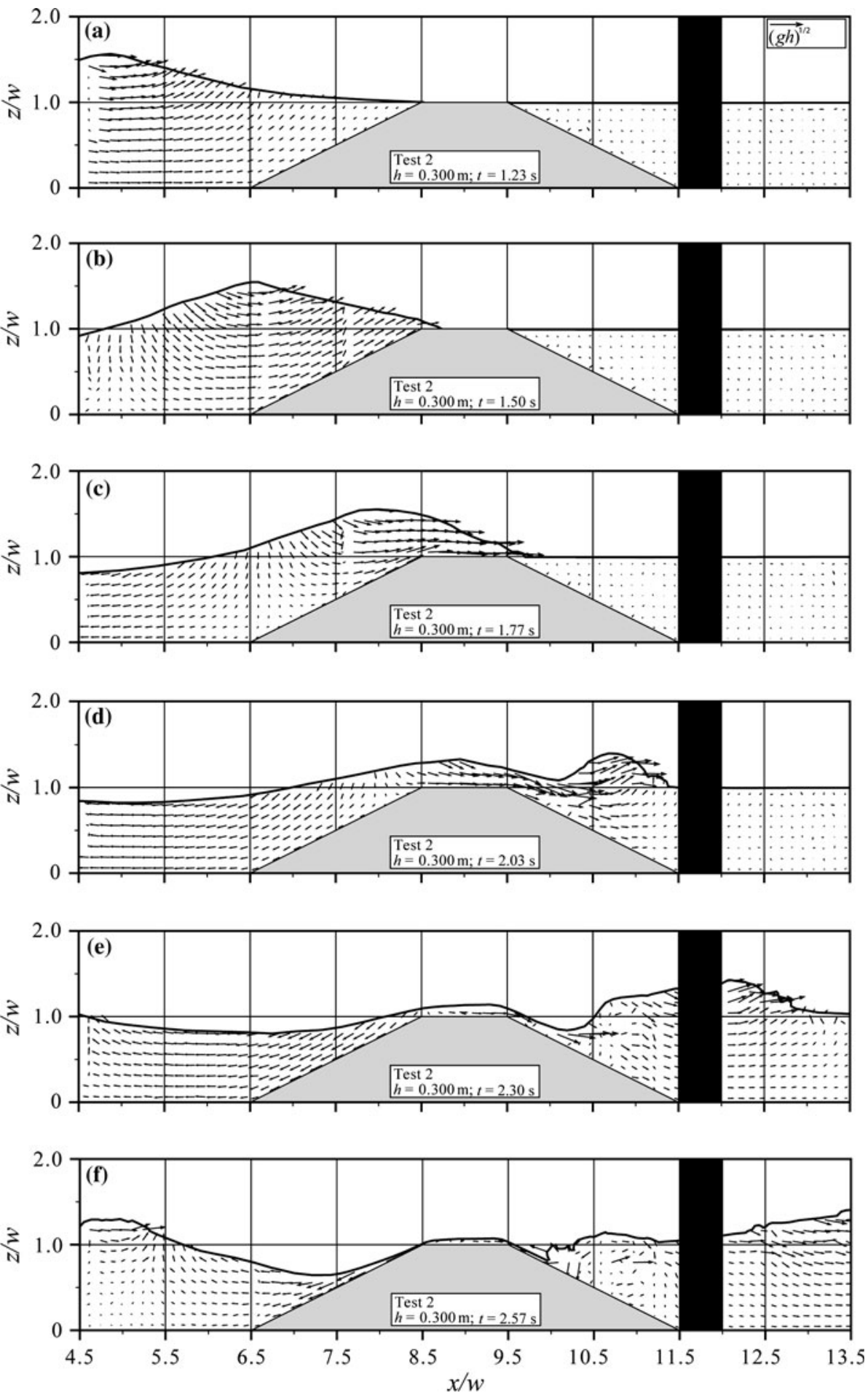

reversal behind the secondary wave is located at $x / w \cong 5.3,6.1,7.7,8.9$ and 9.3 in Fig. 8h-1, respectively. Compared with flow reversal behind the primary wave, this is here much reduced. The tertiary wave from the channel start is observed to enter the field of view in Fig. 8k. Note again that the velocity fields in the bore region are affected by massive air entrainment, reducing the observational quality.

\section{Comparison with basic test without 'breakwater'}

To determine the 'breakwater' effect on the wave characteristics, the wave profiles were compared with the socalled 'basic tests' in which the breakwater was absent (Figs. 9, 10, 11). Each test with breakwater presence was at least tested twice, since the field of view of the velocity vector fields (Figs. 6, 7, 8) is composed of two repetitive 
Fig. 8 Velocity vector fields for Test 3
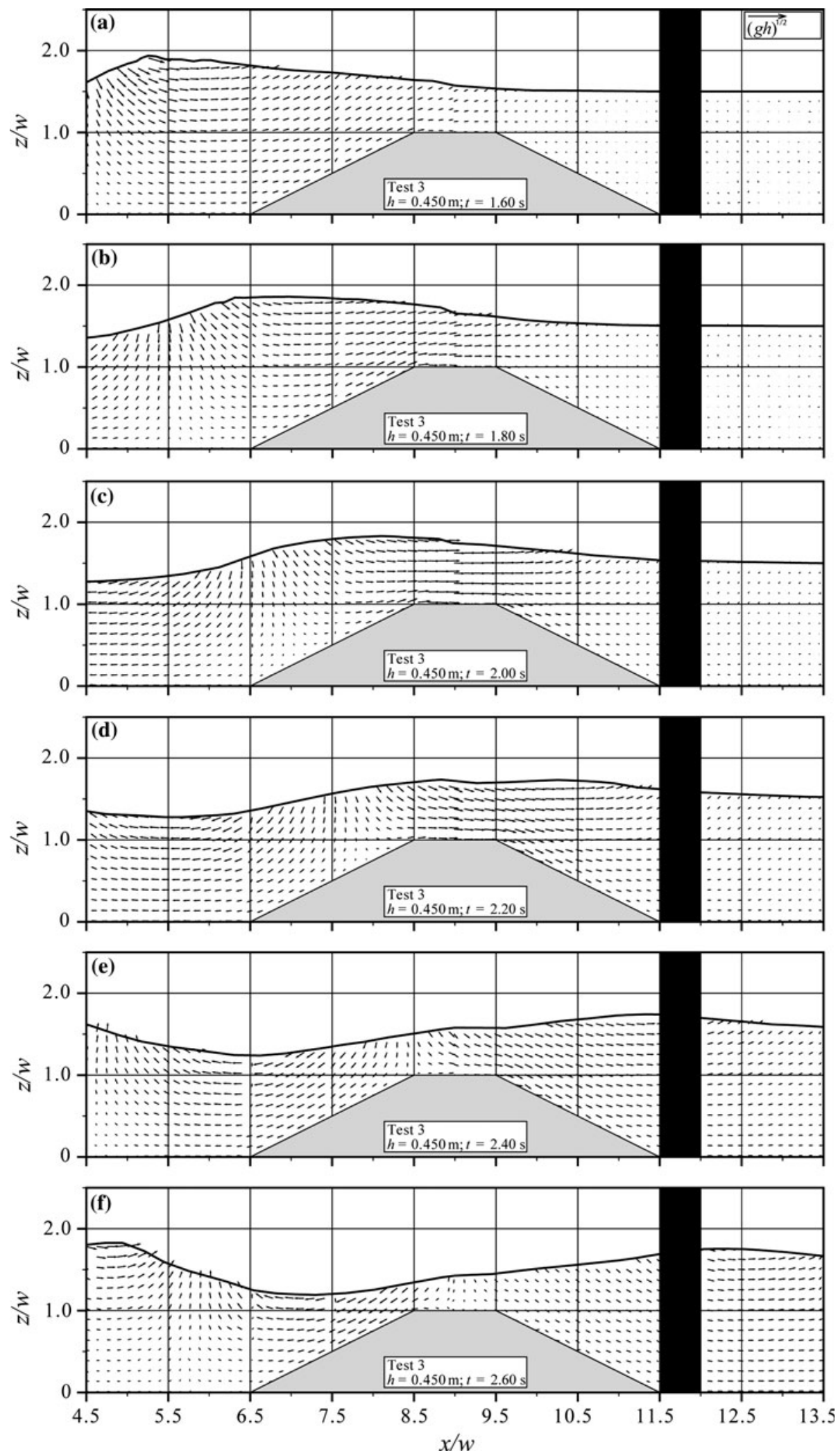

Tests A and B. The dimensionless wave profiles $\eta / h$ in Figs. 9, 10, 11 are shown from top to bottom for the different CWGs measurements. Note that they are normalized with $h$ in contrast to Fig. 6, 7 and 8, where $w$ was used.
As the leading wave profiles of Test 1 in Fig. 9 are equal for both test conditions up to the breakwater toe the wave generation process is hardly affected upstream from the breakwater (Fig. 9a-c), only the wave troughs differ due to 
Fig. 8 continued
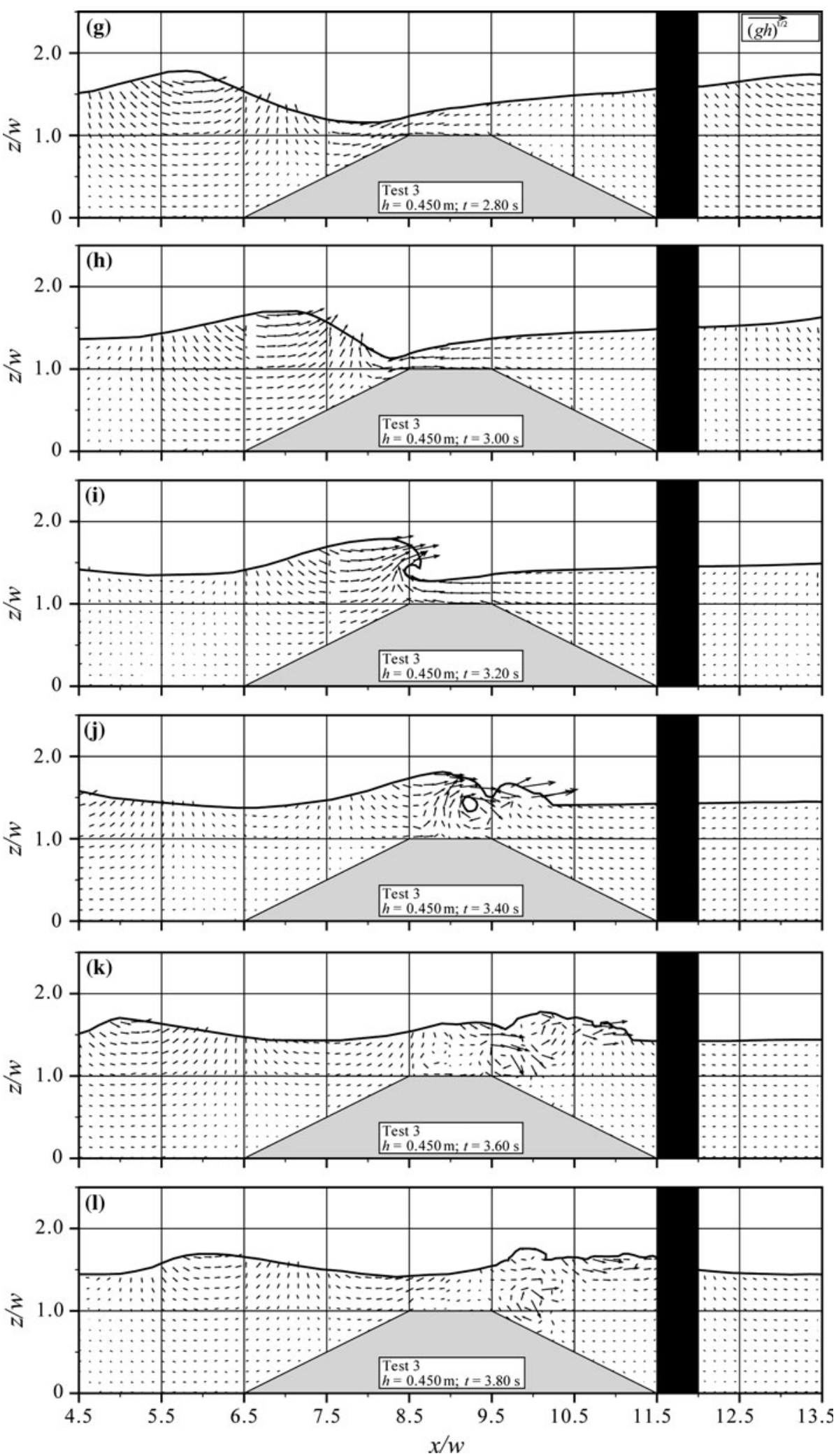

reflection effects from the breakwater. A higher deviation is observed in Fig. 9d where the leading wave amplitude at $t=2.2 \mathrm{~s}$ is slightly larger, and the wave back is slightly less sloped for breakwater presence than in the basic test. A second deviation is particularly seen in Fig. 9c with a significant wave trough at $t=3.8 \mathrm{~s}$ for the tests with 
Fig. 9 Relative wave profiles $\eta / h$ for Tests 1 , with $\mathbf{a}-\mathbf{g}$ for $\mathrm{CWG}_{1}$ to $\mathrm{CWG}_{7}$. Tests A and B are plotted in light and dark grey, whereas basic test is shown in black, respectively
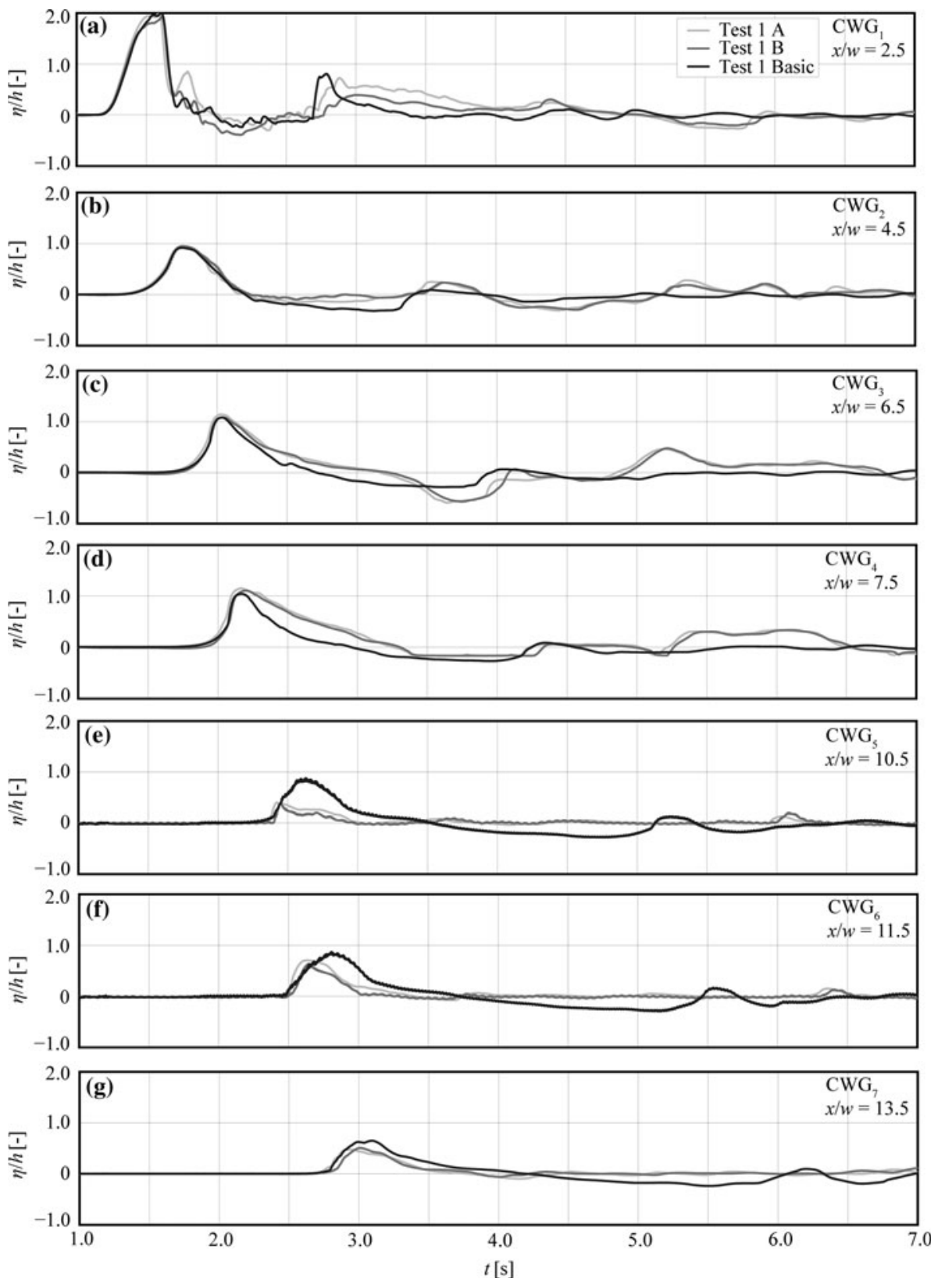

breakwater presence. This effect is generated by the retreating wave portion after the primary wave has overtopped the breakwater (Fig. 3f). Later, the secondary wave generates a second wave peak (Fig. 9c at $t=5.2 \mathrm{~s}$ ).

At position $x / w=10.5$ on the downstream breakwater slope, the wave amplitude of the basic test is more than double of the tests with breakwater presence (Fig. 9e), indicating a reduced flow depth and thus flow acceleration due to jet formation in Tests $1 \mathrm{~A}$ and B. However, a part of these large deviations may also result from the measurement system, since CWGs normally underestimate wave amplitudes consisting of water-air mixture (e.g. Fig. 3c). The wave profiles converge as distance $x$ increases (Fig. 9g). Note the absence of a secondary wave peak downstream of the breakwater for Tests $1 \mathrm{~A}$ and B, and the development of a bore-like wave located at $t=3.0 \mathrm{~s}$ (Fig. 9g). Figure 9e and $\mathrm{f}$ may pretend that the wave propagation celerity is increased by breakwater presence due to the small wave crests at $t=2.4 \mathrm{~s}$ (Fig. 9e) and $2.6 \mathrm{~s}$ (Fig. 9f), whereas the wave crest of the basic test occurs slightly later. However, all wave crests in Fig. $9 \mathrm{~g}$ appear at $t=3.0 \mathrm{~s}$. As the wave passes the breakwater, energy is transformed indicated by a reduced wave amplitude for the test with breakwater presence for an otherwise roughly similar wave profile. For the basic Test 1, the wave celerity of the primary wave $c_{1} \approx 2.24 \mathrm{~m} / \mathrm{s}$ is more than double of the secondary wave with $c_{2} \approx 0.95 \mathrm{~m} / \mathrm{s}$. 
Fig. 10 Relative wave profiles $\eta / h$ for Tests 2, with $\mathbf{a}-\mathbf{g}$ for $\mathrm{CWG}_{1}$ to $\mathrm{CWG}_{7}$. Tests A and B are plotted in light and dark grey, whereas basic test is shown in black, respectively
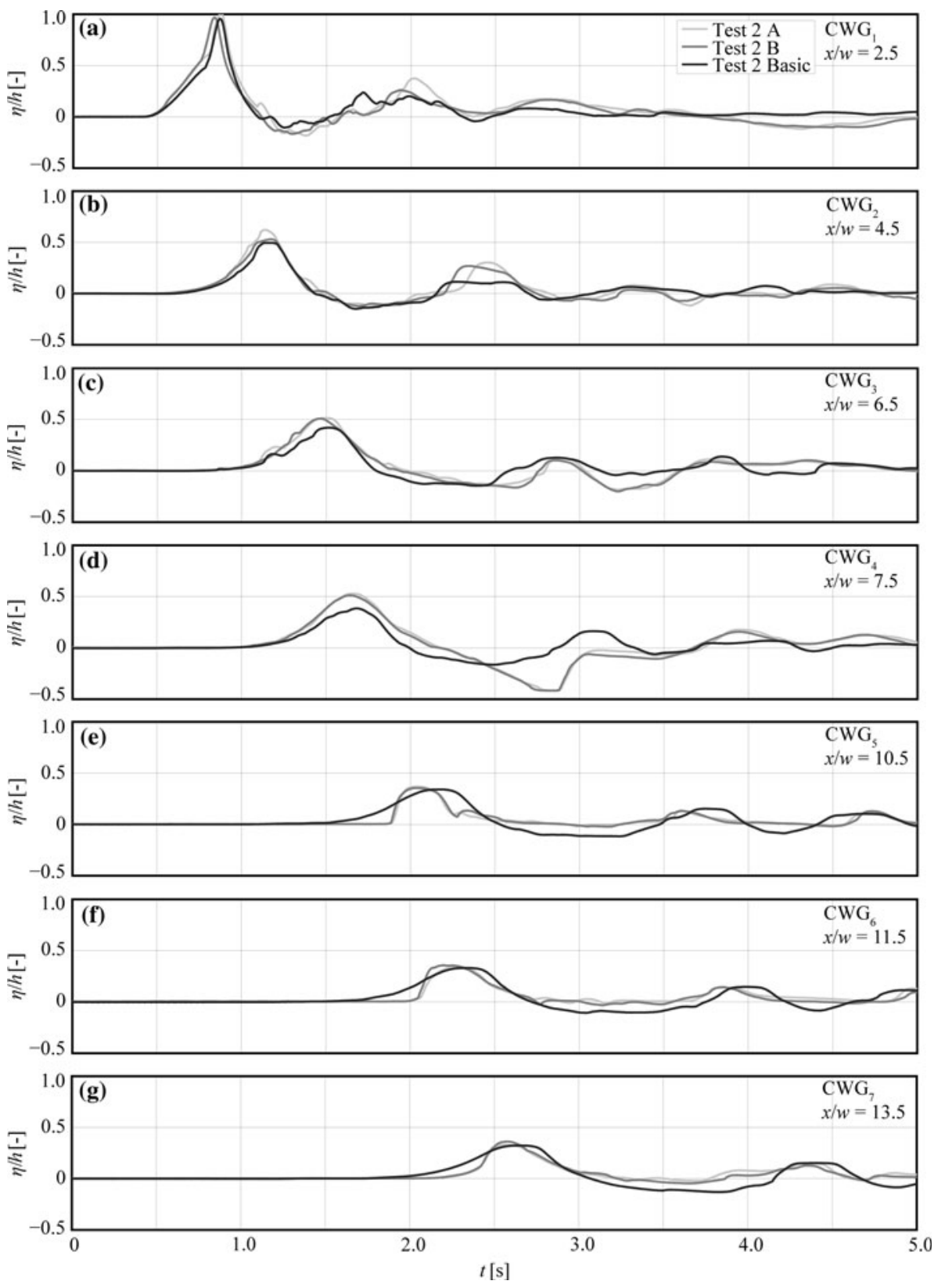

For Test 2, the wave profiles for both test conditions are similar at $\mathrm{CWG}_{1}$ and $\mathrm{CWG}_{2}$ (Fig. 10a, b). Contrary to Test 1 , the amplitude of the primary wave deviates at $\mathrm{CWG}_{3}$. The amplitude differences increase from $22 \%$ in Fig. 10c to $35 \%$ in Fig. 10d. The wave trough visible in Fig. 10d at $t=2.8 \mathrm{~s}$ originates from the wave retreat due to the breakwater presence (Fig. 4e).

Downstream of the breakwater, a bore-like wave is generated by the surface jet, shown as a steep wave front in Fig. 10e-g. The wave profiles of the basic test are cnoidallike with similar wave amplitudes at $\mathrm{CWG}_{5}$ to $\mathrm{CWG}_{7}$. The celerity of the primary wave $c_{1} \approx 1.92 \mathrm{~m} / \mathrm{s}$ is $38 \%$ higher than $c_{2} \approx 1.39 \mathrm{~m} / \mathrm{s}$ of the secondary wave, as compared to
$136 \%$ in Test 1 . The celerities of the two test conditions of Test 2 are almost identical.

The numerical modelling of impulse wave propagation may be simpler calibrated or validated without the complex flow patterns created by breakwater presence. Hence, velocity vector fields for this simplified test configuration without breakwater presence under otherwise identical test conditions are provided in Fig. 11. The primary wave enters the field of view in Fig. 11a. Except for the wave crest, the velocity vectors at the boundary $x / w=4.5$ are mainly horizontal. The wave flattens during propagation and develops its final cnoidal-like profile at $t=2.03 \mathrm{~s}$ with a gentle front and a steeper back slope (Fig. 11d). During 
Fig. 11 Velocity vector fields for Test 2 Basic
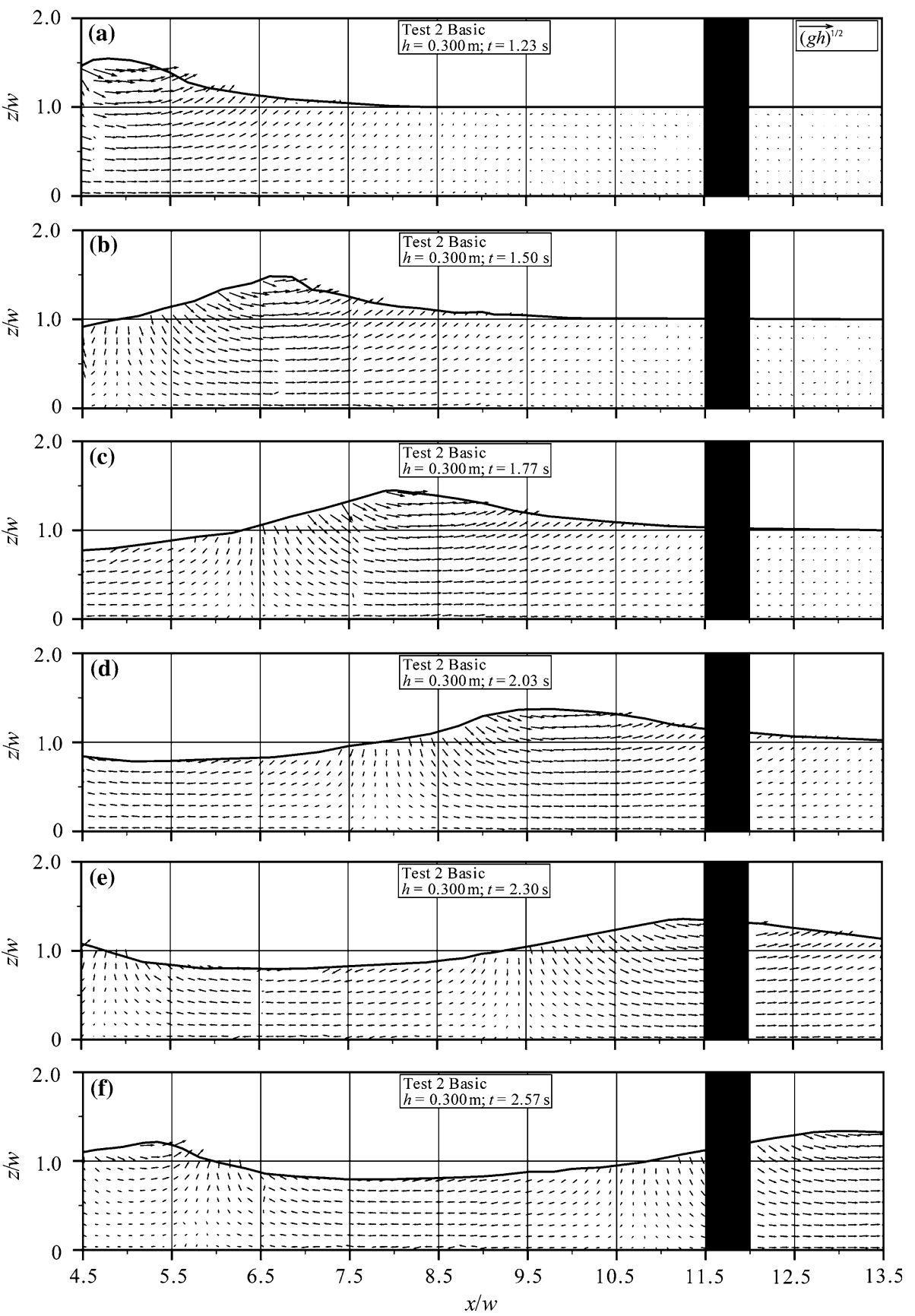

further propagation, the wave profile does not change significantly (Fig. 11d-f). The wave trough height is about $30 \%$ of the primary crest amplitude. With a wave length of $L=7.5 h$, the wave propagates in intermediate-water depth $(2 \leq L / h \leq 20)$, as also indicated by a particle motion at the channel bottom.

In Test 3, hardly any difference in the wave profiles for the primary wave is observed. Only the wave amplitude at $\mathrm{CWG}_{1}$ in Fig. $12 \mathrm{a}$ is slightly smaller for the basic test, coincidentally resulting from the complex three-phase flow in the slide impact zone. The following wave profiles are remarkably similar (Fig. 12b-c). The main breakwater effect therefore is the difference in the temporal evolution of the primary wave peak. Due to the reduced water depth over the breakwater, the wave celerity decreases. The primary and secondary wave crests at $\mathrm{CWG}_{5}$ to $\mathrm{CWG}_{7}$ have a small temporal offset of $\Delta t=0.1 \mathrm{~s}$ between the peaks compared between both test conditions (Fig. 12e-g), yet the amplitudes of the primary waves are similar.

The secondary wave profiles of the basic test and of the corresponding test with breakwater presence differ especially downstream of the breakwater, pointing at the energy transformation caused by the plunging breaker described above. The primary wave celerity of $c_{1} \approx 1.94 \mathrm{~m} / \mathrm{s}$ is by 
Fig. 12 Relative wave profiles $\eta / h$ for Tests 3, with $\mathbf{a}-\mathbf{g}$ for $\mathrm{CWG}_{1}$ to $\mathrm{CWG}_{7}$. Tests A and B are plotted in light and dark grey, whereas basic test is shown in black, respectively
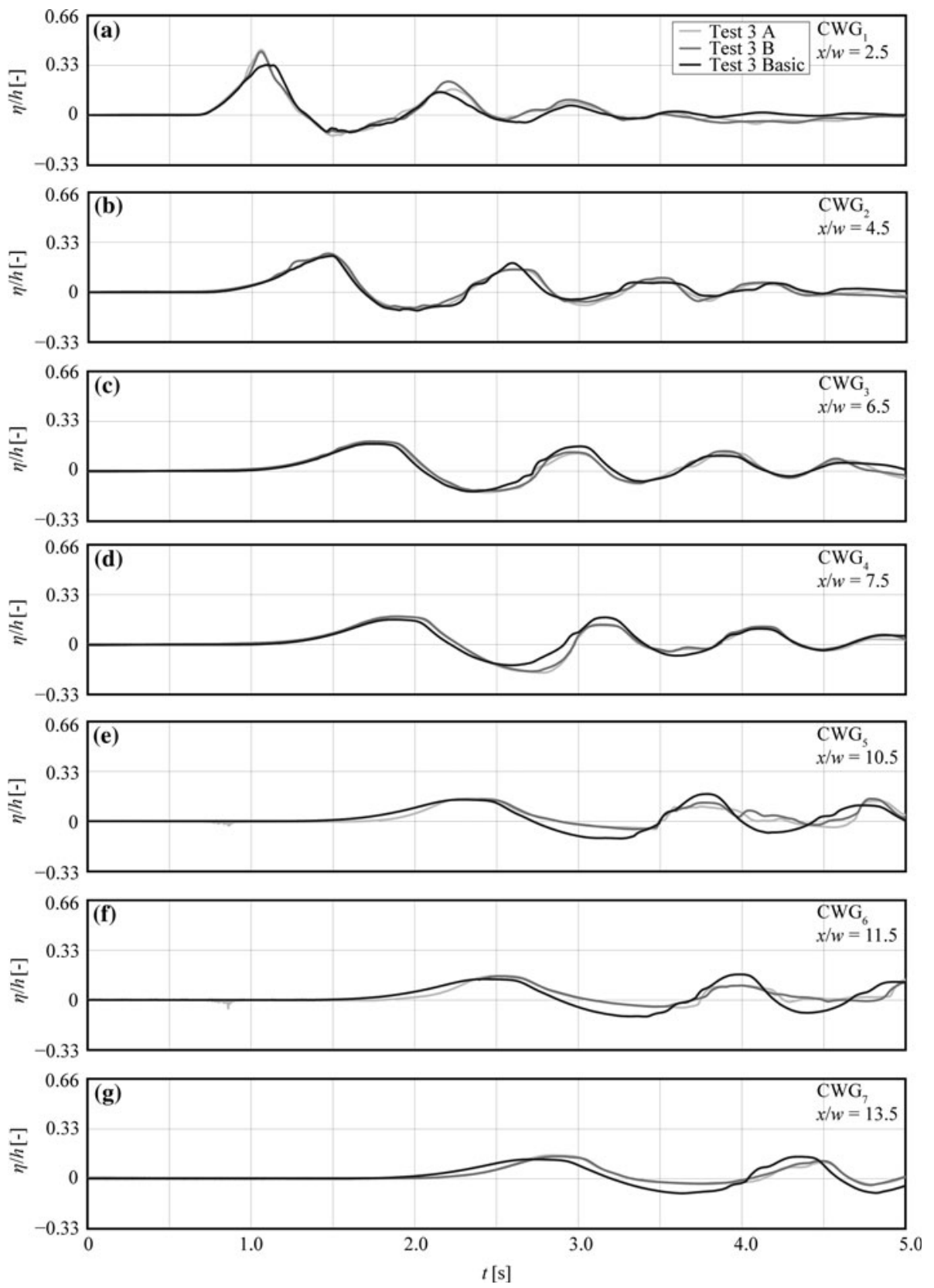

$36 \%$ higher than $c_{2} \approx 1.43 \mathrm{~m} / \mathrm{s}$ of the secondary wave, compared to $136 \%$ in Test 1 and 38\% in Test 2.

\section{Comparison with predictions}

\subsection{Wave amplitude}

The impulse product parameter $\mathrm{P}$ was used to select suitable wave conditions for the three tests with breakwater presence. The resulting wave amplitudes for these were by $8-22 \%$ smaller than predicted by Heller and Hager (2010a), which is below their overall scatter of $\pm 30 \%$, however. The relative streamwise position of the maximum wave amplitude was predicted by Heller and Hager (2010a) by $X_{\mathrm{M}}=(11 / 2) \mathrm{P}^{1 / 2}$, corresponding to $x_{\mathrm{M}} / w=6.07$ in Test $1,7.15$ in Test 2 and 6.85 in Test 3 or roughly at $\mathrm{CWG}_{3}$ in Test 1 and $\mathrm{CWG}_{4}$ in Tests 2 and 3 (Table 2). An inspection of the relative wave profiles (Figs. 9, 10 and 11) indicates maximum wave amplitudes at $x / w=6.5$ in Test 1 and $x / w=4.5$ in Tests 2 and 3, however. Whereas for Test 1 the data match the prediction notably good, the position of the maximum wave amplitude for Tests 2 and 3 is beyond $50 \%$ scatter. $\mathrm{CWG}_{1}$ at $x / w=2.5$ was excluded, because it was much closer to the slide impact zone than in Heller and Hager (2010a). 
Table 4 Ursell number for intermediate-water wave type classification

\begin{tabular}{|c|c|c|c|c|c|c|c|c|c|}
\hline & \multicolumn{3}{|l|}{ Test 1} & \multicolumn{3}{|l|}{ Test 2} & \multicolumn{3}{|l|}{ Test 3} \\
\hline & Test $1 \mathrm{~A}$ & Test $1 \mathrm{~B}$ & Test 1 Basic & Test $2 \mathrm{~A}$ & Test $2 \mathrm{~B}$ & Test 2 Basic & Test $3 \mathrm{~A}$ & Test $3 \mathrm{~B}$ & Test 3 Basic \\
\hline$a_{\max }(\mathrm{m})$ & 0.190 & 0.190 & 0.183 & 0.187 & 0.159 & 0.149 & 0.113 & 0.116 & 9.109 \\
\hline$a_{\min }(\mathrm{m})$ & -0.030 & -0.020 & -0.064 & -0.036 & -0.037 & -0.045 & -0.051 & -0.046 & -0.054 \\
\hline$H(\mathrm{~m})$ & 0.220 & 0.210 & 0.247 & 0.223 & 0.196 & 0.194 & 0.164 & 0.162 & 0.163 \\
\hline$T\left(\mathrm{CWG}_{2}\right)(\mathrm{s})$ & 1.87 & 1.78 & 1.78 & 1.32 & 1.16 & 1.12 & 1.14 & 1.13 & 1.10 \\
\hline$c_{1}(\mathrm{~m} / \mathrm{s})$ & 2.46 & 2.37 & 2.58 & 1.95 & 1.95 & 1.90 & 1.90 & 1.89 & 2.06 \\
\hline$L(\mathrm{~m})$ & 4.60 & 4.22 & 4.59 & 2.57 & 2.26 & 2.13 & 2.17 & 2.14 & 2.27 \\
\hline$U(-)$ & 581 & 466 & 652 & 55 & 37 & 32 & 8 & 8 & 9 \\
\hline
\end{tabular}

Table 5 Criteria for wave type classification

\begin{tabular}{lll}
\hline Criteria & Wave theory & Reference \\
\hline$U \rightarrow 0$ & Linear wave theory & Miles (1980) \\
$U \approx 1$ & Solitary wave theory & Le Méhauté (1976) \\
$U<10$ & Stokes wave theory & Sorensen (1993) \\
$10 \leq U \leq 25$ & Stokes or cnoidal wave theory & Sorensen (1993) \\
$U>25$ & Cnoidal wave theory & Sorensen (1993) \\
$U \gg 1$ & Bore wave theory & Le Méhauté (1976)
\end{tabular}

\subsection{Non-linearity}

Subaerial landslide generated impulse waves are generally non-linear. Table 4 lists the relevant wave parameters in terms of wave non-linearity, namely the maximum and minimum wave amplitudes $a_{\max }$ and $a_{\min }$, wave height $H$, wave period $T$ between two consecutive wave crests at $\mathrm{CWG}_{2}$, primary wave celerity $c_{1}$ and wave length $L=c_{1} \cdot T\left(\mathrm{CWG}_{2}\right)$. The Ursell number $\mathrm{U}=H L^{2} / h^{3}$, defined with $H$ instead of $a$ by Ursell (1953), is an index for wave non-linearity mainly of intermediate-water waves as the ratio of non-linear to dispersive wave effects. Table 5 allows for a rough classification of wave types based on Miles (1980), Le Méhauté (1976) and Sorensen (1993).

The Ursell numbers for Tests 1-3 were determined upstream of the breakwater at $\mathrm{CWG}_{2}$, corresponding to typical wave approach flow conditions. The average of the three individual tests was $U=566$ for Test 1 pointing at a bore-like wave. Test 2 resulted in $U=41$ and thus a cnoidal-like wave, whereas for Test 3 with $U=8.3$, a
Stokes-like wave is generated. Visual observation supports this prediction, as previously described.

Heller and Hager (2010b) determined the wave types based on an optical wave type inspection. They presented a classification that requires only the basic slide parameters which may be estimated prior to slide impact. The wave type product $\mathrm{T}$ combines relative slide thickness $S$, relative slide mass $M$ and slide impact angle $\alpha$ as

$\mathrm{T}=S^{1 / 3} M \cos [(6 / 7) \alpha]$.

Table 6 includes the basic test data, parameter $T$ and the two expressions $(4 / 5) \mathrm{F}^{-7 / 5}$ and $11 \mathrm{~F}^{-5 / 2}$ delimiting the wave types. According to Heller and Hager (2010b), Stokes-like waves occur if $\mathrm{T}<(4 / 5) \mathrm{F}^{-7 / 5}$, cnoidal/solitary-like waves if $(4 / 5) \mathrm{F}^{-7 / 5} \leq \mathrm{T} \leq 11 \mathrm{~F}^{-5 / 2}$, whereas bore-like waves result if $\mathrm{T}>11 \mathrm{~F}^{-5 / 2}$. Accordingly, Test 1 involves a bore-like, Test 2 a cnoidal-like and Test 3 a Stokes-like wave, corresponding to both the predictions previously described and visual observation.

\section{Conclusions}

The complex processes of non-linear impulse wave runover over an artificial breakwater were investigated under simplified 2D test conditions. Three tests involving borelike, cnoidal-like and Stokes-like waves were conducted using the VAW pneumatic landslide generator with a high test repetition accuracy for selected still water depths and slide parameters. This process was documented by

Table 6 Estimated wave types

\begin{tabular}{lllllllllllll}
\hline & $\begin{array}{l}h \\
(\mathrm{~m})\end{array}$ & $\begin{array}{l}s \\
(\mathrm{~m})\end{array}$ & $\begin{array}{l}m_{\mathrm{s}} \\
(\mathrm{kg})\end{array}$ & $\begin{array}{l}\alpha \\
\left({ }^{\circ}\right)\end{array}$ & $\begin{array}{l}V_{\mathrm{s}} \\
(\mathrm{m} / \mathrm{s})\end{array}$ & $\begin{array}{l}\mathrm{F} \\
(-)\end{array}$ & $\begin{array}{l}S \\
(-)\end{array}$ & $\begin{array}{l}M \\
(-)\end{array}$ & $\begin{array}{l}\mathrm{T} \\
(-)\end{array}$ & $\begin{array}{l}(4 / 5) \mathrm{F}^{-7 / 5} \\
(-)\end{array}$ & $\begin{array}{l}11 \mathrm{~F}^{-5 / 2} \\
(-)\end{array}$ & Calculated wave type \\
\hline Test 1 & 0.200 & 0.24 & 55.0 & 90 & 5.69 & 4.06 & 1.20 & 2.9 & 0.682 & 0.112 & 0.331 & Bore \\
Test 2 & 0.300 & 0.24 & 20.6 & 90 & 8.28 & 4.83 & 0.80 & 0.5 & 0.098 & 0.088 & 0.215 & Cnoidal/solitary \\
Test 3 & 0.450 & 0.24 & 20.5 & 90 & 6.24 & 2.97 & 0.53 & 0.2 & 0.038 & 0.174 & 0.724 & Stokes \\
\hline
\end{tabular}


adequate photo records, Particle Image Velocimetry and wave profile measurements. A detailed description allows for calibration and validation of numerical models. In addition, a basic test case without breakwater presence was presented for calibration purposes of non-linear impulse wave modelling.

The wave measurements were compared with predictive formulae resulting in a reasonable agreement for wave amplitudes based on the slide impact characteristics. A good agreement was also found for wave non-linearity using both wave feature measurements and slide impact characteristics compared with visual observations.

A complete set of experimental data containing both the slide profile prior to impact and the run-over processes along with vector information for the test without breakwater presence was only presented for Test 2 . The full data set for all three tests can be requested from the first author.

Acknowledgments The first author was supported by the Swiss National Science Foundation, Grant 200020_119717/1.

\section{References}

Ataie-Ashtiani B, Shobeyri G (2008) Numerical simulation of landslide impulsive waves. Int J Numer Meth Fluids 56:209-232

Dalrymple RA, Rogers BD (2006) Numerical modelling of water waves with the SPH method. Coast Eng 53:141-147. doi: 10.1016/j.coastaleng.2005.10.004

Falappi S, Gallati M (2007) SPH simulation of water waves generated by granular landslides. Proceedings of the 32nd Congress of IAHR Venice 933:1-10. IAHR, Madrid

Fritz HM, Moser P (2003) Pneumatic landslide generator. Int J Fluid Power 4(1):49-57

Fritz HM, Hager WH, Minor H-E (2001) Lituya Bay case: rockslide impact and wave run-up. Sci Tsunami Hazards 19(1):3-22

Fritz HM, Hager WH, Minor H-E (2003) Landslide generated impulse waves. 1. Instantaneous flow fields. Exp Fluids 35:505-519. doi: 10.1007/s00348-003-0659-0

Grilli ST, Losada MA, Martin F (1994) Characteristics of solitary wave breaking induced by breakwaters. J Waterw Port Coast Ocean Eng 120(1):74-92. doi:10.1061/(ASCE)0733-950X(1994) 120:1(74)

Heller V (2007) Landslide generated impulse waves-prediction of near field characteristics. Ph.D. Thesis 17531, ETH Zurich, Zurich
Heller V, Hager WH (2010a) Impulse product parameter in landslide generated impulse waves. J Waterw Port Coast Ocean Eng (accepted)

Heller V, Hager WH (2010b) Wave types in landslide generated impulse waves. Ocean Eng (submitted)

Heller V, Hager WH, Minor H-E (2008) Scale effects in subaerial landslide generated impulse waves. Exp Fluids 44:691-703. doi: 10.1007/s00348-007-0427-7

Huang C-J, Dong C-M (2001) On the interaction of a solitary wave and a submerged dike. Coast Eng 43(3-4):265-286. doi: 10.1016/S0378-3839(01)00017-5

Kamphuis JW, Bowering RJ (1972) Impulse waves generated by landslides. In: Proceedings of 12th Coastal Engineering Conference, Washington DC, vol 1. ASCE, New York, pp 575-588

Le Méhauté B (1976) An introduction to hydrodynamics and water waves. Springer, New York

Liu PL-F, Synolakis CE, Yeh HH (1991) Report on the international workshop on long-wave run-up. J Fluid Mech 229:675-688

Liu PL-F, Yeh H, Synolakis C (2008) Advanced numerical models for simulating tsunami waves and runup. Advances in coastal and ocean engineering, 10. World Scientific, Singapore

Mader CL, Gittings ML (2002) Modeling the 1958 Lituya Bay megatsunami, II. Sci Tsunami Hazards 20(5):11-43

Miles JW (1980) Solitary waves. Annu Rev Fluid Mech 12:11-43

Montes S (1998) Hydraulics of open channel flow. ASCE Press, Reston VA

Panizzo A, De Girolamo P, Petaccia A (2005) Forecasting impulse waves generated by subaerial landslides. J Geophys Res 110(C12025):1-23. doi:10.1029/2004JC002778

Quecedo M, Pastor M, Herreros MI (2004) Numerical modelling of impulse wave generated by fast landslides. Int $\mathbf{J}$ Numer Meth Eng 59:1633-1656

Reeve D, Chadwick A, Fleming C (2004) Coastal engineering: processes, theory and design practice. Taylor \& Francis, London UK

Schnitter G (1964) Die Katastrophe von Vaiont in Oberitalien (in German). Wasser- und Energiewirtschaft 56(2/3):61-69

Schwaiger HF, Higman B (2007) Lagrangian hydrocode simulations of the 1958 Lituya Bay tsunamigenic rockslide. Geochem Geophys Geosyst 8(7):Q07006

Sorensen RM (1993) Basic wave mechanics for coastal and ocean engineers. Wiley, New York

Ursell F (1953) The long-wave paradox in the theory of gravity waves. Proc Camb Philos Soc 49:685-694

Weiss R, Wuennemann K (2007) Understanding tsunami by landslides as the next challenge for hazard, risk and mitigation: insight from multi-material hydrocode modeling. In: EOS Transactions AGU, San Francisco, 88(52):S51C-06

Zweifel A, Zuccalà D, Gatti D (2007) Comparison between computed and experimentally generated impulse waves. J Hydraul Eng 133(2):208-216 